\title{
Introduction: Design Innovation for Society
}

\author{
Nynke Tromp ${ }^{\mathrm{a}}$ and Mieke van der Bijl-Brouwer ${ }^{\mathrm{b}}$ \\ aUniversity of Technology, Sydney \\ ${ }^{\mathrm{b}} \mathrm{TU}$ Delft \\ DOI: $10.21606 / \mathrm{drs} .2016 .628$
}

What an exciting time for design it is. Instead of being merely concerned with the creation of artefacts, contemporary design may now seek ways to shape governance structures in Indonesia, may facilitate dialogue about the risks and challenges of self-presentation online, or may seek social transformation for people in vulnerable positions. Clearly, designers and scholars involved here are not concerned about revenue, but about social value: about improving the way people live together. With this goal in mind, the designer is no longer on solid ground, but enters the realm of politics. She needs to lever between power structures, engage various stakeholders, and advocate new ways of thinking. Which role the designer could or maybe should adopt in innovation processes that aim for social good is not clearly articulated yet. We are at the stage of experimenting and exploring what roles the designer can play and what value this brings. Nevertheless, the notion that current societies are in urgent need for new approaches and solutions clearly fosters the bravery to invite the creative to the public domain. Because not only do designers wish to 'do good' and move into social design practice, also the public sector increasingly acknowledges that creative thinkers and new relationships with citizens are needed. In this new discipline of design, we see focus on the social system that is coping with the problem and/or has potential in contributing to the solution, or a focus on the object of design, which can be a boundary object for facilitating the innovation processes, or the eventual outcome of design. In reference to the papers included in this theme, we provide an overview of contemporary research within design innovation for society and raise three important issues that revolve around the theme.

To be able to move from a commercial design practice to design innovation for society, we need a practice that produces products, services and interventions that generate value for society. This is not only about generating innovative ideas, but also about the implementation of them and the continuous delivery of public value, or in other words, providing service. Addressing complex societal challenges often includes developing services. 
And because the nature of these problems is networked (Dorst, 2015), the design of services requires collaboration between stakeholders across different organisations and disciplines (Sørensen \& Torfing, 2012). Collaborative services for complex social issues are usually provided through the public sector, but can also be created and delivered through publicprivate innovation networks (Gallouj, Rubalcaba, \& Windrum, 2013); through voluntary and community associations, business and professional and citizen groups (Kelly, Mulgan, \& Muers, 2002) or through a process of 'co-production' in which citizens and state work together to produce public outcomes (Christiansen \& Bunt, 2014). As such, the boundaries between service users and service providers are blurry and increasingly overlapping, resulting in a complex service system.

To be able to design for such complex service systems requires that designers understand the complexity of these systems and find ways to ensure that the various stakeholders in the system will adopt new service concepts. This includes an understanding of the boundaries of what can and cannot be designed or controlled in a complex system. One way to look at this is through the organisations and people within organisations that collectively constitute a complex service system. Opposing the management discourse based on technical rationality that assumes that organisations are systems which can be controlled, Stacey and Griffin (2006, p30) state that organisations are not actually existing things called systems but, rather, are ongoing, iterated patterns of relationships between people. The global patterns we recognize as complex service systems, such as the health service or the educational service, are continually emerging in these myriad local interactions (ibid, p39). This suggests that we cannot completely design or prescribe complex service systems, but that we can try to design for them.

Indeed we can observe a trend that design practices in the public realm are increasingly aimed at designing 'infrastructures' that influence the relationships between stakeholders in the system, rather than designing service concepts for end-users. For example, MindLab recently designed a 'speed-sharing event' that allows the municipality of Odense to support primary school teachers in sharing knowledge with each other to improve their teaching (Nygaard \& Reynolds, 2015). Rather than designing an 'educational service' for children and their parents (the end-users), the project was aimed at improving the infrastructure of that service that influences the relationships between teachers, and the relationship between teachers and the municipality.

To be able to design for such complex service systems puts designers in a role of 'mediator' between service providers, and between service providers and service users. As a mediator the designer facilitates a dialogue between stakeholders - through for example co-design practices or boundary objects - aiming at a reciprocal understanding of their needs and perspectives. However, the designer-mediator role is not only about facilitating this dialogue. It also requires expertise to use the understanding of the stakeholders to inform the development of interventions that allow for the emergence of new patterns of relationships between the people within the complex service system. These new patterns of relationships can then lead to new (bottom-up) strategies to create value for society. The 
speed sharing event designed by MindLab, led to new relationships between teachers, which in turn resulted in new bottom-up teaching strategies to create value for children in schools.

Not surprisingly, for many, societal innovation goes hand in hand with participatory processes. And this has led to valuable results: the focus on underlying needs and concerns of stakeholders fosters open dialogue, and thereby the space to not only improve the outcome of design, the service, but equally so the provision of the service: its governance. Van der Bijl-Brouwer illustrates effectively how a new 'frame' may unite stakeholders in deciding upon a new way of working, one in which earlier obstacles could be overcome and in which service-users can actually become part of the service provision. In a similar line of thinking, Torres Castanedo \& Micklethwaite illustrate nicely how a co-design approach may activate people to recognise and exchange their human capability to strengthen the social welfare of the community. Through workshops and creative sessions with end-users as well as service providers, ideas were developed that as such did not require new resources but foremost human capital. Given both the work of Durrant et al. and Cooney et al., such processes could benefit from visual narratives that act as boundary objects: either to be able to integrate research findings in one's work as public servant, or as a way to make sense of the topic at hand and discuss this together. Torres Castanedo \& Micklethwaite's focus on human capital is in line with what Munro advocates for in his paper. Given the fact that social design often revolves around problems, and people who have problems, Munro argues that designers should prevent this problem-oriented approach and shift to a design process that aims for social transformation. Equally seeking to improve the wellbeing of vulnerable people through design, Whitehead, Evans \& Bingham present a tool to improve the new product development process to ensure designs fit the social context of people living in poverty. In contrast to the societal innovation processes that start with a social objective, both Rosenqvist \& Mitchell and Kempenaar start off with an existing public design, and put forward design approaches to improve the design and/or its governance. Kempenaar focuses on regional design and illustrates the parallels their process revealed with participatory design. Discussing three levels of governance -direct governance (first), the vision that guides governance (second), and the values and norms that govern this governance (third)- Rosenqvist \& Mitchell study how a design approach could also influence more directly the second and third order governance. In their view, the designed environment, the products and services can make governance structures tangible for people and thereby empower them, similar to design activism. These papers show how design is capable of improving the organisation and governance of services, maybe even more than offering new ideas for services. The papers show that design can support occupational rehabilitation, mental health care, wastewater management, elderly care, poverty, and digital literacy. Bringing this to the educational domain, Cattoir-Brisson at al. have placed the concept of project centre to the development of their curriculum to teach and study social innovation by design in projects with public partners. In their view, social innovation relies on the relatively recently adopted agency-model in design, yet its goal can be traced back to the origin of design: improving the quality of our shared existence. In how to constitute this 
quality or societal value, students are taught conceptual frameworks from the social sciences and humanities and are taught how to coordinate multiple stakeholder processes.

Although many designers and design scholars are currently developing methods and tools to support societal innovation by design, little is said about how social value is exactly defined: what does betterment of society mean? The very fact that there might be no 'right answer' to this question may be one of the reasons co-design is often the route designers take. Thorpe and Gamman argue this indeed "necessitates a co-design approach that is plural and equitable regarding the agency of actors within the design process" (Thorpe \& Gamman, 2011 , p. 219). And clearly, the papers in this theme reveal its value. Nonetheless, we wish to address three issues that may lead to problems in the future when we do not account for them.

Firstly, the fact that stakeholders often provide input in response to the current context, i.e., the (problematic) situation that exists at the moment. In other words, what they consider important, valuable or desirable has been framed by the existing system. But examining today's problems using today's lens can only partly help to understand how to design for a better society: we also need the knowledge, the theories and philosophies that help us to understand what makes a viable community in the long term. So similar to how a politician is informed both by everyday experiences (which admittedly is lacking in current politics) and science/knowledge, so too should the social designer lean on both channels for understanding.

Secondly, 'human-centred' design is not the same as 'society-centred' design. Many explain designers' human-centeredness as particularly valuable for the public sector, considering that many societal systems, like education and health care, have grown so large that the human touch is often lost. From the macro view, we agree that a human perspective is crucial. However, in adopting this perspective it is important to understand that what may be desirable from an end-user perspective (the type of perspective many designers regularly take) can easily conflict with what is best for society as a whole. Social design inevitably deals with competing interests - known as social dilemmas -in which individual concerns and social interests conflict (Van Lange \& Joireman, 2008) and can actually offer unique solutions for resolving these (Tromp, 2013).

Finally, it can be argued that what most people want is not necessarily 'good'. Including the wants of every stakeholder in the design decision-making process may have less than desirable ethical implications. There are, however, philosophers who can help us articulate 'what is good'; not to provide a single 'correct' answer, but to guide decision-making partly from a moral standpoint. For example, the products and services we develop for health and education also define which people are 'sick' or 'dumb'. Prescriptions such as these may not be readily apparent in the design of a single device, but when we develop a national electronic patient file system, they are. Using values to guide design decisions for such systems is already quite common (e.g., Value-Sensitive Design; Friedman, Kahn, \& Borning, 2002). Since social design is inherently dealing with trade-offs between conflicting concerns, ascertaining the value-related dimension of a design is unquestionably central to social 
design and innovation methodology, especially for large-scale transformations in the public sector.

\section{References}

Christiansen, Jesper, \& Bunt, Laura. (2014). Innovating public policy: allowing for social complexity and uncertainty in the design of public outcomes. In C. Bason (Ed.), Design for Policy. Farnham Surrey, England: Gower Publishing Limited.

Dorst, Kees. (2015). Frame Innovation; create new thinking by design. Cambridge, Massachusetts: The MIT Press.

Friedman, B., Kahn, P. H., \& Borning, A. (2002). Value Sensitive Design: Theory and Methods. Univeristy of Washington technical report, 02-12.

Gallouj, Faïz, Rubalcaba, Luis, \& Windrum, Paul. (2013). Public-private innovation networks in services (ServPPINs). In F. Gallouj, L. Rubalcaba \& P. Windrum (Eds.), Public-Private Innovation Networks in Services (pp. 1-20). Cheltenham, UK: Edward Elgar.

Kelly, Gavin, Mulgan, Geoff, \& Muers, Stephen. (2002). Creating Public Value: An analytical framework for public service reform. UK: Strategy Unit, Cabinet Office Retrieved from http://webarchive.nationalarchives.gov.uk/20100416132449/http:/www.cabinetoffice.gov.uk/stra tegy/seminars/public_value.aspx.

Nygaard, Lene, \& Reynolds, Sophie. (2015). Creation solutions for Danish teachers: the time and quality dilemma. from http://www.nesta.org.uk/blog/creating-solutions-danish-teachers-timeand-quality-dilemma-0

Sørensen, Eva, \& Torfing, Jacob. (2012). Introduction Collaborative Innovation in the Public Sector. The Innovation Journal: The Public Sector Innovation Journal, 17(1), 1-14.

Stacey, R., \& Griffin, D. (2006). Complexity and the Experience of Managing in Public Sector Organizations. New York: Routledge.

Tromp, N. (2013) Social Design: How products and services can help us act in ways that benefit society. Delft Univeristy of Technology: PhD thesis.

Van Lange, P. A. M., \& Joireman, J. A. (2008). How We Can Promote Behavior That Serves All of Us in the Future. Social Issues and Policy Review, 2(1), 127-157. 
This page is left intentionally blank 